\title{
Impact of urban heat island on inorganic aerosol in the lower free troposphere: a case study in Hangzhou, China
}

Hanqing Kang ${ }^{1,2,3}$, Bin Zhu ${ }^{1,2}$, Gerrit de Leeuw ${ }^{1,4,5,6}, \mathrm{Bu} \mathrm{Yu}^{7}$, Ronald J. van der $\mathrm{A}^{1,4}$, Wen $\mathrm{Lu}^{1,2}$

${ }^{1}$ Key Laboratory for Aerosol-Cloud-Precipitation of China Meteorological Administration, Nanjing

${ }^{2}$ Collaborative Innovation Center on Forecast and Evaluation of Meteorological Disaster, Nanjing University of Information Science and Technology, Nanjing 210044, China

${ }^{3}$ Chongqing Institute of Meteorological Sciences, Chongqing 401147, China

${ }^{4}$ KNMI (Royal Netherlands Meteorological Institute), R\&D Satellite Observations, P.O.Box 201,

10 3730AE De Bilt, The Netherlands

${ }^{5}$ Aerospace Information Research Institute, Chinese Academy of Sciences (AirCAS), Beijing 100101, China

${ }^{6}$ University of Mining and Technology (CUMT), School of Environment Science and Spatial Informatics, Xuzhou 221116, China

$15{ }^{7}$ Hangzhou Meteorological Bureau, Hangzhou 310051, China

Correspondence to: Bin Zhu (binzhu@nuist.edu.cn) and Bu Yu (fengying5457@163.com)

\section{Abstract.}

Urban heat island (UHI) and urban air pollution are two major environmental problems faced by many metropolises. The UHI affects air pollution by changing the local circulation and the

20 chemical reaction environment, e.g., air temperature and relative humidity. In this study, the WRFCMAQ model was used to investigate the impact of an UHI on the vertical distribution of aerosol particles, especially secondary inorganic aerosol (SIA), taking the strong UHI in Hangzhou, China, as an example. Results show that due to the UHI effect, $\mathrm{PM}_{2.5}$ concentrations over Hangzhou decreased by about $26 \%$ in the boundary layer (BL) but increased by about $21 \%$ in the lower free troposphere (LFT). This is mostly attributed to the UHI circulation $(\sim 90 \%)$ rather than changes in the air temperature $(\sim 5 \%)$ and humidity $(\sim 4 \%)$. The UHI circulation not only directly transports aerosol particles from ground level to the LFT, but also redistributes aerosol precursors. About $80 \%$ of the increase of the aerosol particles in the LFT due to the UHI circulation effect is contributed by direct transport of aerosol particles, whereas the other $20 \%$ is due to secondary aerosol formation resulting from the transport of aerosol precursor gases. Of this $20 \%$, secondary inorganic aerosol (SIA), especially nitrate and ammonium aerosol formed from ammonia and nitric acid, contributes $91 \%$. In the atmosphere, ammonium nitrate is in equilibrium with ammonia and nitric acid and the equilibrium depends on the ambient temperature. In the lower urban BL, the temperature is higher than in the LFT and the ammonium nitrate equilibrium in the lower BL is more toward the gas phase than in the LFT; when these gases are transported by the UHI circulation into the colder LFT, the equilibrium shifts to the aerosol phase. Hence, the UHI circulation changes the vertical distribution of SIA, which may have potential implications on the radiation budget, cloud formation, and precipitation in the urban and surrounding areas.

\section{Introduction}

With the fast economic development, China has experienced rapid industrialization and urbanization in the past decades. The urbanization process has replaced natural land surface with 
artificial constructions. The radiative, aerodynamic, thermal and moisture properties of these urban constructions are radically different from the natural landscape. Lower albedo, larger energy storage, higher Bowen ratio, and the release of anthropogenic heat in urban areas, leading to the urban heat island (UHI) phenomenon (Oke et al., 2017; Rotach et al., 2005). Meanwhile, the increase in fossil fuel consumption and the rapid growth of the population have led to a sharp increase in anthropogenic emissions in urban areas, resulting in serious urban air pollution problems such as haze and photochemical smog (Zhao et al., 2017; Wang et al., 2019; Gao et al., 2017). Crutzen (2004) pointed out that the UHI and air pollution are far from being independent phenomena but co-existing.

Urbanization affects local meteorological conditions, which in turn influences the distribution and formation of air pollutants. UHI leads to strong thermal convection and diffusion, which promotes the vertical transport of heat, water vapor, and atmospheric pollutants from ground level to the upper atmosphere, and subsequently affects cloud formation, precipitation, and chemical reactions (Kang et al., 2014; Li et al., 2019; Zhu et al., 2015; Zhong et al., 2015). The vertical transport of water vapor caused by urban thermal convection is the source of water for cloud formation and precipitation (Baik et al., 2006), resulting in the increase of precipitation in the city and downwind (Changnon, 1979; Wan et al., 2013). Variations in cloud cover and precipitation will inevitably impact the liquid phase chemistry of aerosol and the wet removal of air pollutants.

The UHI effect also affects chemical processes in the urban atmosphere. The increase in air temperature accelerates certain chemical cycles in the atmosphere, most of which lead to enhanced ground-level ozone production (Narumi et al., 2009). The UHI circulation can also affect chemical reactions by changing the distribution of air pollutants and their precursors. Zhu et al. (2015) indicated that the UHI circulation transports $\mathrm{NO}_{x}$ and VOCs, the precursors of $\mathrm{O}_{3}$, from ground level to higher altitudes, leading to a significant increase in the photochemical production of $\mathrm{O}_{3}$ there. The impact of the UHI effect on $\mathrm{PM}_{2.5}$ is very complicated. Liu et al. (2016) suggested that the UHI circulation and high surface roughness in urban areas reduce the horizontal wind speed at ground level, and hence suppress the outflow of air pollutants, resulting in the increase of $\mathrm{PM}_{2.5}$. In contrast, other studies indicated that UHI reduces ground level aerosol concentration by enhancing turbulent mixing in deeper urban boundary layer (BL) (Zhu et al., 2017; Li et al., 2018; Liao et al., 2015). Several studies have investigated the impact of UHI on aerosol, but few of them focused on how UHI affects the secondary formation of inorganic aerosols, such as sulfate, nitrate, and ammonium. These scattering aerosols can attenuate incident solar radiation, leads to an overall cooling of the surface, inhibits the development of PBL (Li et al., 2017; Ma et al., 2020). In addition, sulfate and nitrate aerosol particles are very hygroscopic and thus act as cloud condensation nuclei in a high relative humidity environment (Tao et al., 2012). Therefore, the vertical distribution and secondary formation of inorganic aerosol in the urban environment plays an important role in the local radiation budget, cloud formation and precipitation.

In this study, a strong UHI case that occurred in Hangzhou on 18 September, 2017, was chosen to investigate the impact of the UHI effect on the distribution and formation of $\mathrm{PM}_{2.5}$ and its inorganic components. We conducted four simulations using the regional meteorological model WRF coupled with the chemical transport model CMAQ to simulate the UHI effect and quantify the impact of UHI-induced variations in circulation, temperature, and humidity on secondary inorganic aerosol (SIA). This paper is organized as follows. Section 2 describes the model configuration, experiment design, and verification. The UHI effect and its impact on $\mathrm{PM}_{2.5}$ and its inorganic components are presented in section 3 and the conclusions in section 4 . 


\section{Model Description and Verification}

\subsection{Model Description and Configuration}

The WRF model version 3.9.1 coupled with a multilayer building energy parameterization (BEP) urban canopy model was employed to simulate the UHI effect and provide the meteorological fields for the chemical transport model. The model was set up with three nested domains (Fig. 1a) with horizontal grid numbers (grid spacing) of 300×300 (9 km), 240×240 (3 km), and 140×140 (1 $\mathrm{km})$. The innermost domain was centered at Hangzhou city, which is surrounded by croplands and mixed forests (Fig. 1b). The model was divided vertically into 37 sigma levels, the lowest 20 of which are below $2 \mathrm{~km}$ to better resolve the processes within the BL. A 10-day simulation (from 00:00 UTC 10 September to 00:00 UTC 20 September 2017) was conducted with the initial conditions (ICONs) and the outermost boundary conditions (BCONs) from the National Center for Environmental Prediction's $1^{\circ}$ grid spacing operational Global Forecast System final analyses. The fine resolution (30 s) Moderate Resolution Imaging Spectroradiometer (MODIS) 20 category land use data were used to represent the urban land type in the innermost domain. Two experiments were designed to investigate the UHI effect of Hangzhou city. The first, known as CTL simulation, used MODIS land use data as the default surface (with Hangzhou city) description for the control experiment; the second, NUB simulation, was a sensitivity experiment, in which the urban land use of Hangzhou city was replaced by cropland. By comparison of the result from the two experiments, the UHI effects of Hangzhou city can be identified.

The CMAQ model version 5.0.2 was applied to simulate concentrations of gaseous and particulate air pollutants with the same grid settings as the WRF model. The output of the two WRF experiments (CTL and NUB) provided the meteorological inputs for CMAQ simulations. The CMAQ simulations cover the same time period as the WRF simulations with the first 2 days used as spin-up time. The ICONs and BCONs for the outermost domain of the CMAQ simulations were 110 derived from the Model for Ozone and Related Chemical Tracers version 4 (MOZART-4) (Emmons et al., 2010). The BCONs for the CMAQ nested domains were extracted from the immediate concentration files of their parent domains. The monthly Multi-resolution Emission Inventory for China (MEIC, http://www.meicmodel.org/, last accessed: July 20, 2021) with the reference year of 2017 was used for anthropogenic emissions except for Hangzhou. The anthropogenic emissions in

115 Hangzhou were derived from Hangzhou Municipal Ecology and Environment Bureau's anthropogenic emission survey in 2016 with horizontal grid space of $1 \mathrm{~km} \times 1 \mathrm{~km}$. Biogenic emissions were generated from the Model for Emissions of Gases and Aerosols from Nature (MEGAN) version 2.1 (Guenther et al., 2012). Sea-salt and dust emissions were calculated online.

It should be noted that all simulation experiments use the same emission inventory. Therefore, the impact of the UHI on aerosol properties can be derived from the difference between the CTL and NUB CMAQ simulations. In order to identify the impact of the UHI-induced changes in temperature, humidity, and circulation (the UHI circulation is caused by the increased temperature in the urban area, but temperature and temperature-induced circulation affect air pollutants in different ways) on the aerosol properties, two additional sensitivity experiments were designed. One 125 is the TMP simulation, in which the air temperature used in the aerosol module where the SIA formation was calculated, was derived from the NUB simulation, other parameters kept the same as in the CTL simulation. The other one is the T\&H simulation, in which the air temperature and specific humidity were derived from the NUB simulation, while other parameters kept the same as 
in the CTL simulation. The difference between CTL and TMP simulations indicates the UHI temperature effect on aerosol. By comparing the CTL and T\&H simulations, the overall effect from temperature and humidity can be derived. Hence the humidity and circulation effects can be separated. Details of the experimental designs are provided in table 1.

Table 1. Configuration of CMAQ experiments

\begin{tabular}{lll}
\hline Experiment & \multicolumn{1}{c}{ Configuration } & \multicolumn{1}{c}{ Effect } \\
\hline CTL & CTL meteorology from WRF. & \\
NUB & NUB meteorology from WRF. & CTL-NUB: Overall UHI effect on aerosol. \\
& $\begin{array}{l}\text { CTL meteorology but using } \\
\text { TMP }\end{array}$ & $\begin{array}{l}\text { NUB temperature in aerosol } \\
\text { module. }\end{array}$
\end{tabular}

CTL-T\&H: UHI temperature effect + UHI

CTL meteorology but using $\mathrm{T} \& \mathrm{H} \quad$ NUB temperature and specific humidity in aerosol module. humidity effect on aerosol. $(\mathrm{CTL}-\mathrm{T} \& \mathrm{H})-(\mathrm{CTL}-\mathrm{TMP})=\mathrm{TMP}-\mathrm{T} \& \mathrm{H}: \mathrm{UHI}$ humidity effect on aerosol. (CTL-NUB)-(CTL-T\&H) $=$ T\&H-NUB: UHI circulation effect on aerosol.

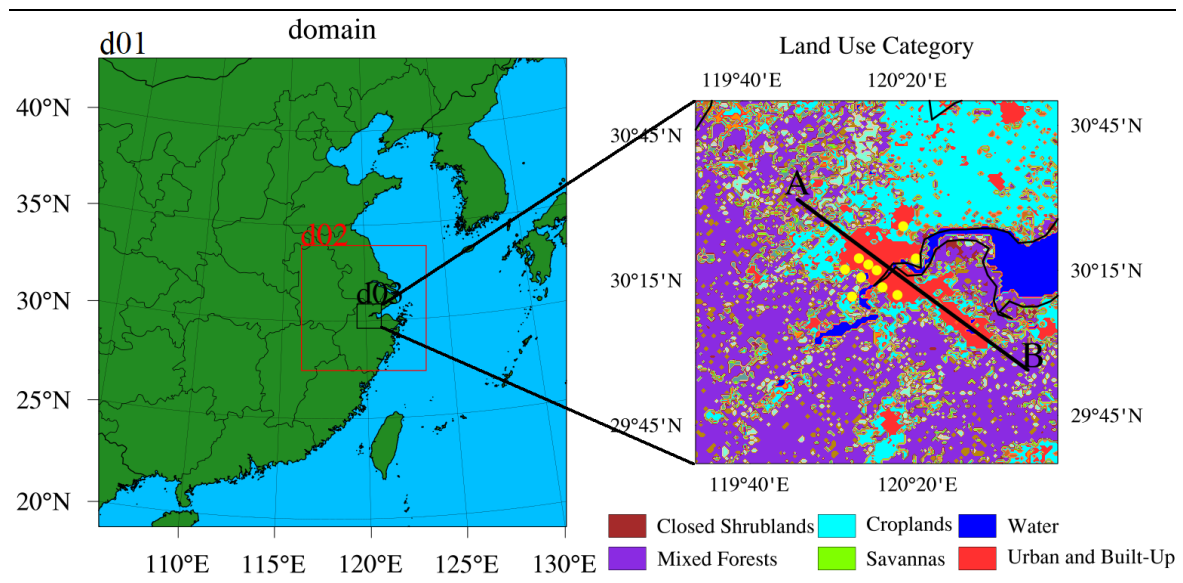

135 Figure 1. The three nested modeling domains (a) and land use categories over the innermost domain (b). The horizontal spacing for domain $\mathrm{d} 01, \mathrm{~d} 02$, and $\mathrm{d} 03$ are $9 \mathrm{~km}, 3 \mathrm{~km}$, and $1 \mathrm{~km}$, respectively. The line $\mathrm{AB}$ in (b) denotes the location of the vertical cross section shown in Fig. 3 and Fig. 4. The yellow solid circles represent locations of the $10 \mathrm{PM}_{2.5}$ monitoring sites.

\subsection{Model Evaluation}

140 The model performance for the $\mathrm{PM}_{2.5}$ concentrations in Hangzhou was extensively evaluated on an hourly scale, using surface measurements in 10 observation sites (yellow solid circles in Fig. 1b) released by the China National Environmental Monitoring Center (CNEMC). Statistical metrics including the correlation coefficient, normalized mean bias (NMB), normalized mean error (NME), index of agreement (IOA), mean fractional bias (MFB), and mean fractional error (MFE) were

145 calculated to compare the model simulations with observations. The NMB, NME, MFB, and MFE were calculated as follows:

$N M B=\frac{\sum_{i=1}^{N}\left(M_{i}-O_{i}\right)}{\sum_{i=1}^{N} O_{i}} \times 100 \%$ 
$150 \quad M F B=\frac{2}{N} \sum_{i=1}^{N}\left(\frac{M_{i}-O_{i}}{M_{i}+O_{i}}\right) \times 100 \%$

$M F E=\frac{2}{N} \sum_{i=1}^{N}\left(\frac{\left|M_{i}-O_{i}\right|}{M_{i}+O_{i}}\right) \times 100 \%$

where $\mathrm{M}_{\mathrm{i}}$ is the hourly simulated $\mathrm{PM}_{2.5}$ concentration, $\mathrm{O}_{\mathrm{i}}$ is the hourly observed $\mathrm{PM}_{2.5}$ concentration, and $\mathrm{N}$ denotes the number of data pairs.

Time series of hourly $\mathrm{PM}_{2.5}$ concentrations from both the CTL simulation and observations at

155 the 10 CNEMC sites are compared in Fig. 2. The CTL simulation captures the diurnal variations and magnitude of $\mathrm{PM}_{2.5}$ well at most of the sites. The correlation coefficient, NMB and NME between observations and CTL simulations at the 10 monitoring sites are shown in Fig. 3a. The correlation coefficients were $>0.6$ except for one site. The NMBs at all sites were within $\pm 30 \%$, and all NMEs were $<60 \%$. The IOA, MFB and MFE at each site (Fig. 3b) show a pattern similar to that for the correlation coefficients, NMB and NME, respectively. The average correlation coefficient, NMB, NME, IOA, MFB and MFE of the 10 sites are $0.68,0.5 \%, 44.7 \%, 0.78,-12 \%$ and $45.4 \%$, respectively. To evaluate the impact of urban land surface on ground level $\mathrm{PM}_{2.5}$ simulation, the NUB simulations were also compared with the observations. The results from these comparisons show that if the Hangzhou urban surface is replaced by cropland, the ground level $\mathrm{PM}_{2.5}$ concentration would be larger by approximately $60 \%$ (NMB for NUB experiment is $60 \%$ ) and simulation error would increase by approximately $30 \%$ (NME for NUB experiment is $74 \%$ ). These results suggest that the urban land surface and UHI effect exert an important impact on urban air quality. 

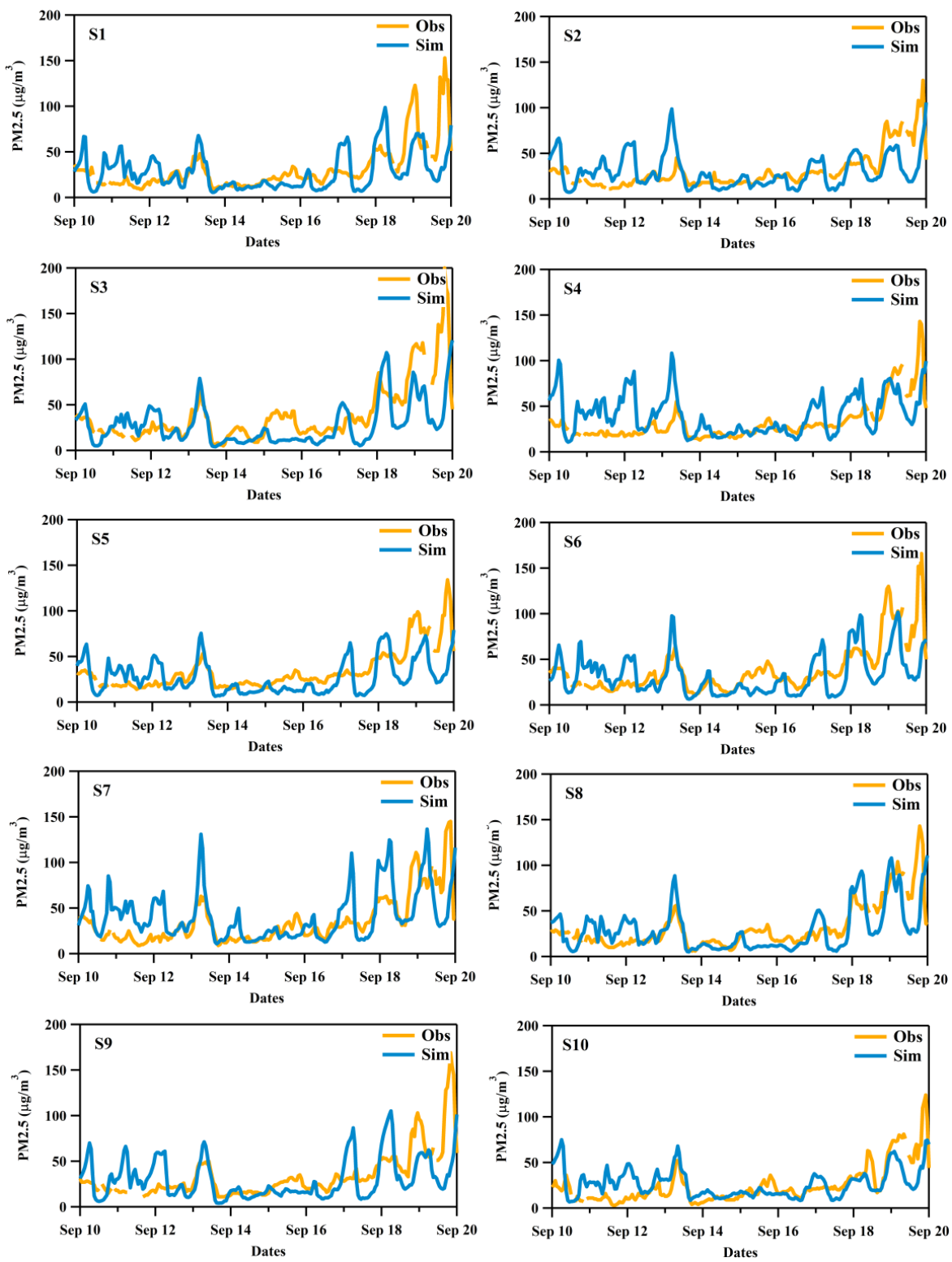

Figure 2. Time series of simulated and observed $\mathrm{PM}_{2.5}$ concentration from 00:00 LT September 10 to 00:00 LT September 20, 2017 at 10 monitoring sites. 

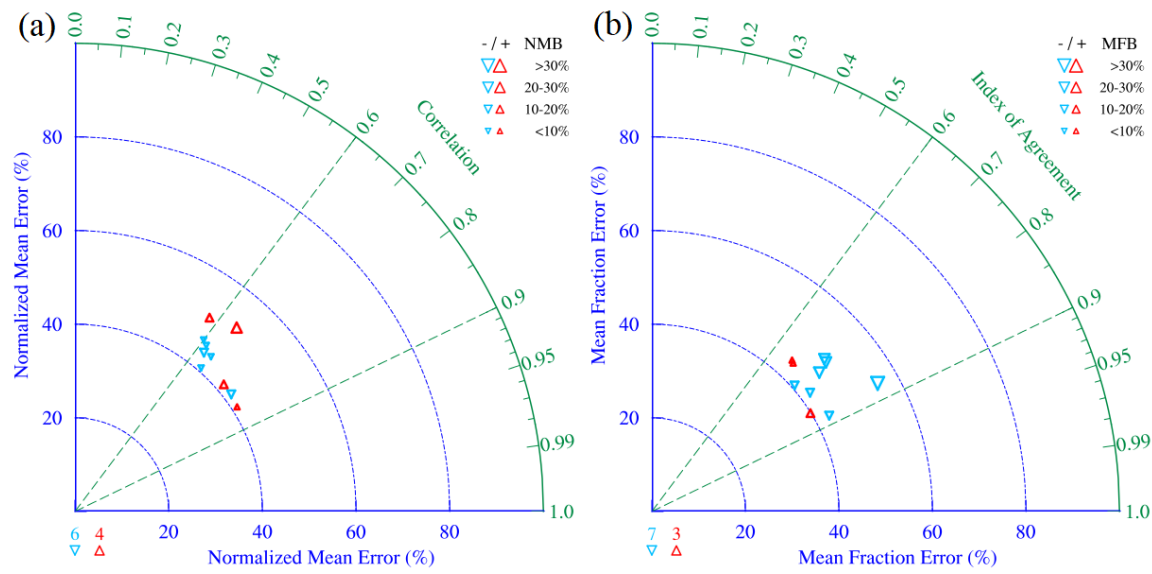

Figure 3. Taylor diagram of (a) correlation coefficient, normalized mean bias (NMB) and normalized mean error (NME); (b) index of agreement (IOA), mean fractional bias (MFB) and mean fractional error (MFE) between simulated (CTL experiment) and observed $\mathrm{PM}_{2.5}$ concentrations at 10 sites in Hangzhou (yellow solid circles in Fig. 1b).

\section{Results and Discussion}

The UHI affects the concentrations of atmospheric pollutants and their spatial and vertical distribution by changing local circulation and chemical reaction environment, e.g., air temperature and humidity, in the overlying atmospheric column. The impacts of these effects over Hangzhou and its surrounding area were investigated by comparison of the meteorological parameters simulated in the CTL experiment with those from the NUB experiment. In the 10-day experiment, the strongest UHI effect occurred on September 18, 2017, which will be discussed in the following sections.

\subsection{Urban Heat Island Effect}

The time-averaged (12:00-17:00 LT September 18, 2017) vertical distribution of air temperature, relative humidity, and wind vectors in the CTL experiment along line AB (see Fig. 1b) over Hangzhou show an obvious UHI effect, which is characterized by the higher air temperature, lower relative humidity, and stronger upward movement over the urban area than over the surrounding rural areas (Fig. S1). The difference in the air temperature, specific humidity and wind between CTL and NUB experiments along line AB show that the warming, drying, and circulation effects of the UHI reach an altitude of $2.0 \mathrm{~km}$. Kang et al. (2014) suggested that the maximum surface UHI intensity occurs in the evening, while the strongest UHI circulation appears in the afternoon. The UHI circulation plays a prominent role in the horizontal and vertical distributions of air pollutants in urban atmosphere (Zhu et al., 2015). The changes in the air temperature and specific humidity may potentially affect the secondary formation of aerosols. Meanwhile, the average BLH over Hangzhou in the CTL simulation was approximately $1.0 \mathrm{~km}, 0.3 \mathrm{~km}$ higher than that in NUB simulation. The deeper BL is the result of the stronger turbulence which is due to the warmer urban surface. As a result, the air pollutants are mixed over a deeper BL. The UHI circulation clearly shows the convergence in the lower BL and the strong upward transport accompanied by intermittent 
compensation downdrafts over urban area. The altitude that the UHI circulation can reach depends on the coverage of the urban area. The vertical branches of UHI circulation penetrate the top of the urban BL $(\sim 1.0 \mathrm{~km})$ to reach the lower free troposphere (LFT) $(\sim 2.0 \mathrm{~km})$ (Fig. 4), which may have significant effects on the vertical transport of aerosol and its precursors.

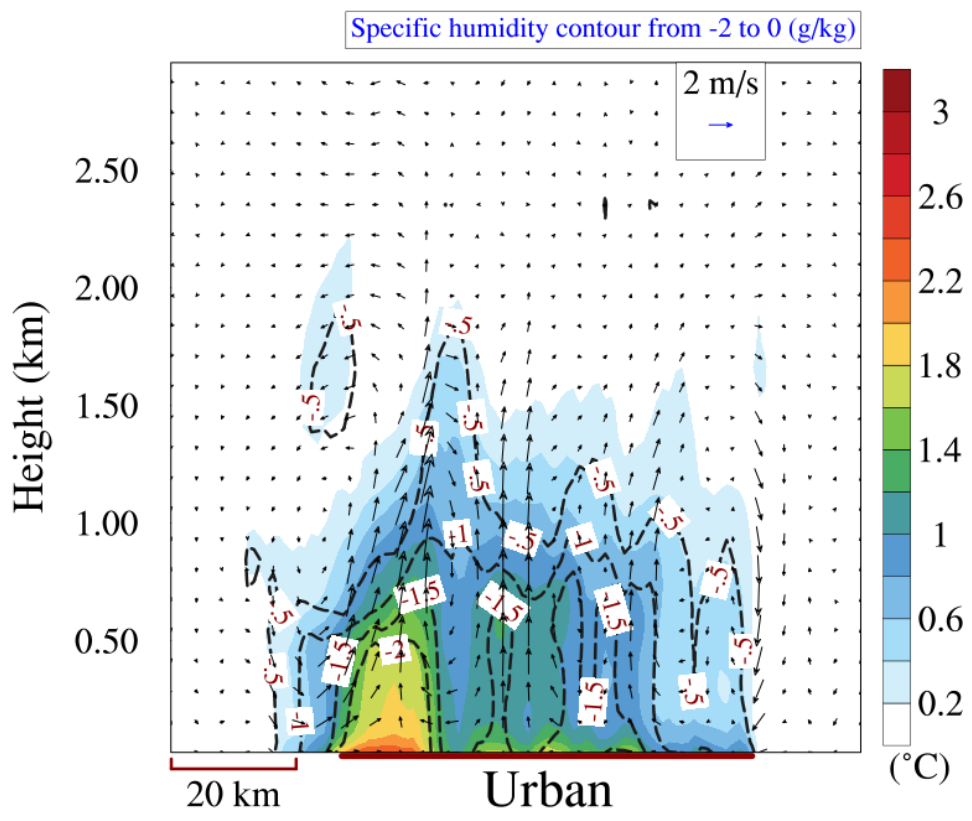

Figure 4. Averaged (12:00-17:00 LT September 18, 2017) vertical cross section of the difference in temperature (filled colors), specific humidity (dashed contour lines), and in-plane vectors (arrows) between the CTL and NUB experiments (CTL-NUB). Note that the vertical speed vectors are expanded by 10 times.

\subsection{Impact of the UHI on $\mathrm{PM}_{2.5}$}

In the CTL experiment, the vertical distribution of $\mathrm{PM}_{2.5}$ along the line $\mathrm{AB}$ shows higher $\mathrm{PM}_{2.5}$ concentration and much deeper aerosol layer over the urban area than over the surrounding rural (Fig. S2). To evaluate the UHI effect on the $\mathrm{PM}_{2.5}$ vertical distribution, the cross section of differences of the $\mathrm{PM}_{2.5}$ and in-plane wind vectors between the CTL and NUB experiments along the line $\mathrm{AB}$ are shown in Fig. 5. The $\mathrm{PM}_{2.5}$ differences show that $\mathrm{PM}_{2.5}$ concentrations in the $\mathrm{BL}$ decreased, on average with $8.5 \mu \mathrm{g} \mathrm{m}^{-3}(26 \%)$ and increased in the LFT, on average with $2.9 \mu \mathrm{g} \mathrm{m}^{-3}$ (21\%). Similar UHI effects were obtained by WRF-Chem model simulations in the Yangtze River Delta (Liao et al., 2015), south China (Zhu et al., 2017) and California (Li et al., 2019), respectively. 


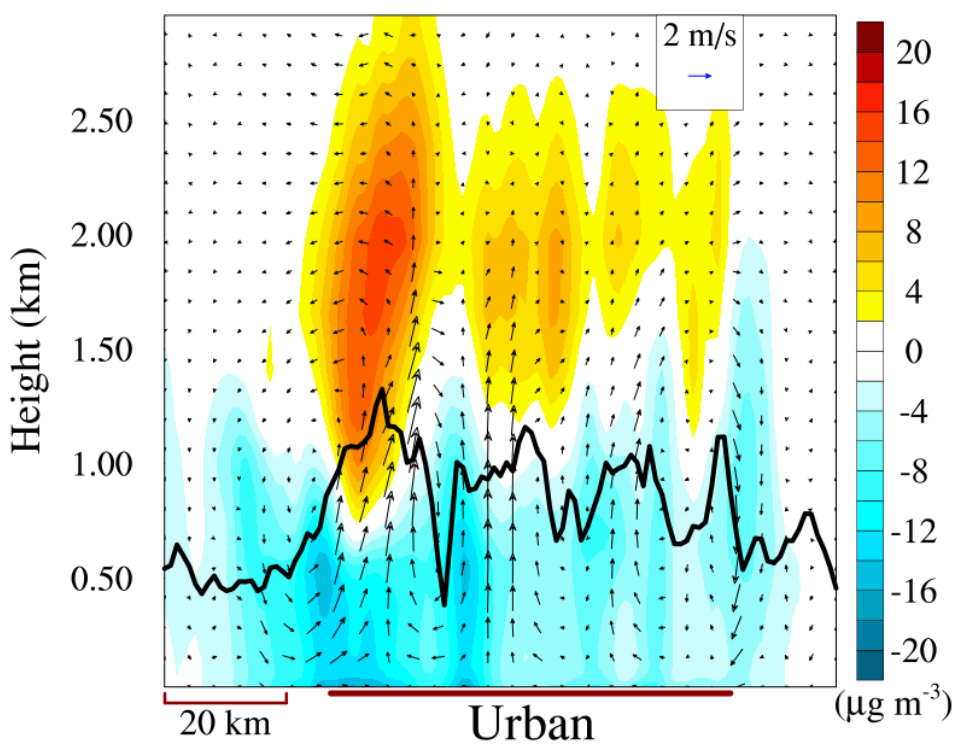

Figure 5. Averaged (12:00-17:00 LT September 18, 2017) vertical cross section of the difference in $\mathrm{PM}_{2.5}$ and in-plane wind vectors between the CTL and NUB experiments. Note that the vertical speed is expanded by a factor 10 . The black line denotes the BL height.

In addition to influencing the distribution of the concentrations of aerosol particles and precursor gases by changing the local circulation, the UHI also affects the secondary formation of aerosol by changing the air temperature and the humidity. By comparing the four experiments (Table 1), the contributions of the changes in temperature, humidity, and circulation to the vertical distribution of the $\mathrm{PM}_{2.5}$ concentrations over Hangzhou can be identified. Figure 6 shows the vertical profiles of the $\mathrm{PM}_{2.5}$ concentrations from the CTL, NUB and T\&H simulations and the effects of several processes on them. The difference between the $\mathrm{PM}_{2.5}$ concentration profiles from the CTL and $\mathrm{T} \& \mathrm{H}$ simulations is very small as compared to the difference between the CTL and NUB simulations (left panel in Fig. 6. The $\mathrm{PM}_{2.5}$ profile from the TMP simulation is not shown in the picture, because it is very close to the profiles from the CTL and T\&H simulations.). The simulations show that the effects of air temperature and humidity on the $\mathrm{PM}_{2.5}$ concentration account for only $9.7 \%$ of the total UHI effect, of which the contributions of temperature and humidity are $5.3 \%$ and $4.4 \%$, respectively, while the contribution from the circulation effect accounts for about $90 \%$.

To further investigate how the UHI affects the vertical distribution of $\mathrm{PM}_{2.5}$ by changing physical and chemical processes, a process analysis technique was performed (Fig. 6). The profiles of the area-averaged $\mathrm{PM}_{2.5}$ contribution from the vertical advection process (ZADV) show that in the CTL experiment the negative contributions $\left(-25 \mu \mathrm{g} \mathrm{m} \mathrm{m}^{-3}\right.$ on average) in the middle and lower part of the BL are higher than in the NUB experiment $\left(-5 \mu \mathrm{g} \mathrm{m}^{-3}\right.$ on average) whereas in the LFT the CTL contributions are positive $\left(14 \mu \mathrm{g} \mathrm{m}^{-3}\right.$ on average) and stronger than in the NUB experiment (2 $\mu \mathrm{g} \mathrm{m}^{-3}$ on average). This suggests that the UHI circulations induce the transport of aerosol from the lower part of the BL to the upper part and into the free troposphere. The difference in horizontal 245 advection process (HADV) between the CTL and NUB experiments indicates that the UHI circulation results in stronger convergence $\left(21 \mu \mathrm{g} \mathrm{m}^{-3}\right)$ of aerosol in the $\mathrm{BL}$ and stronger divergence $\left(-15 \mu \mathrm{g} \mathrm{m}^{-3}\right)$ in the LFT. 
The vertical diffusion process (VDIF) results in uniform mixing of $\mathrm{PM}_{2.5}$ in the $\mathrm{BL}$. In the afternoon of September 18, 2017, the mean BL height over Hangzhou was about $1 \mathrm{~km}$. Stronger turbulent mixing in the CTL experiment due to higher temperature and urban surface roughness resulted in higher urban BL height and smaller $\mathrm{PM}_{2.5}$ vertical gradient than that in NUB experiment. Since the emissions of $\mathrm{PM}_{2.5}$ are near the surface, there is a strong negative contribution from vertical diffusion near ground level (Fig. 6). The positive contributions in the middle and lower BL $(<0.8 \mathrm{~km})$, indicating that vertical diffusion transports aerosol from ground level to the upper atmosphere by turbulent mixing. Weak negative $\mathrm{PM}_{2.5}$ contributions $\left(\sim-1 \mu \mathrm{g} \mathrm{m}^{-3}\right)$ from vertical diffusion, especially in CTL experiment, appears in upper BL and LFT.

The contributions of aerosol process (AERO) to $\mathrm{PM}_{2.5}$ concentrations were negative $\left(-3 \mu \mathrm{g} \mathrm{m}^{-3}\right.$ on average) in the lower BL $(<0.4 \mathrm{~km})$, but positive $\left(4 \mu \mathrm{g} \mathrm{m}^{-3}\right.$ on average $)$ in the upper air $(0.4 \sim 2.0$ $\mathrm{km}$ ) (Fig. 6), which suggests that the aerosols were dissociated in the lower BL while they formed in the upper air. Under the influence of UHI, a much stronger secondary aerosol formation occurs in the upper BL and the LFT. This is probably due to the transport of aerosol precursors from ground level to the upper air by the UHI circulation.

In the LFT, the UHI circulation contributed $\sim 95 \%$ (the average contribution from ground level to LFT is $\sim 90 \%$ ) of the aerosol increase. Process analysis shows that vertical advection (ZADV) and aerosol (AERO) processes are responsible for this increase. The differences between the ZADV and the AERO contributions from the T\&H and NUB simulations show that direct vertical advection of aerosol contributes $80 \%$ of the UHI circulation-induced aerosol increase in the LFT, secondary formation of aerosol from vertically transported aerosol precursors contribute the remaining $20 \%$ of the UHI circulation effect.

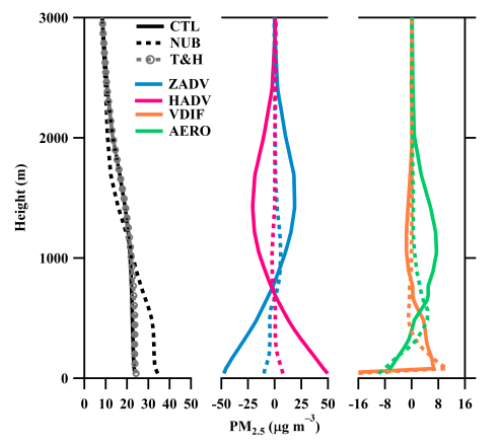

Figure 6. Averaged (12:00-17:00 LT September 18, 2017) vertical profiles of $\mathrm{PM}_{2.5}$ concentrations from the CTL (solid line), NUB (dashed line) and T\&H (dashed line and circle) experiments and contributions of vertical advection (ZADV), horizontal advection (HADV), vertical diffusion (VDIF), and aerosol (AERO) processes to $\mathrm{PM}_{2.5}$ concentration from CTL and NUB experiments.

\subsection{Impact of the UHI on Inorganic Aerosol}

To quantify the impact of the UHI on the dissociation and formation of SIA over the urban atmosphere, the process analysis technique was applied. The results in Fig.7 show that the UHI affects the vertical distribution of sulfate mainly through circulation rather than secondary formation (Fig. 7a). The negative contributions of the aerosol process to $\mathrm{PM}_{2.5}$ in the lower BL are mostly attributed to the dissociation of ammonium nitrate (Fig. 7b, 7c). Meanwhile, the positive 
contributions of the aerosol process in the upper air are mostly attributed to the secondary formation of ammonium nitrate aerosol. The formation and dissociation of ammonium nitrate aerosol involves an equilibrium reaction between the particle-phase $\mathrm{NH}_{4} \mathrm{NO}_{3}$, and gas-phase $\mathrm{HNO}_{3}$ and $\mathrm{NH}_{3}$ :

$$
\mathrm{NH}_{4} \mathrm{NO}_{3}(\mathrm{~s}) \rightleftharpoons \mathrm{HNO}_{3}(\mathrm{~g})+\mathrm{NH}_{3}(\mathrm{~g}) . \quad(6)
$$

Process analysis shows that the aerosol process makes positive contributions to ammonia and nitric acid in lower BL but negative contributions in the upper atmosphere (Fig. 8) - the opposite of the result from ammonium nitrate aerosol. This finding supports the conclusion that ammonium nitrate aerosols were formed in the upper atmosphere but dissociated in lower BL.
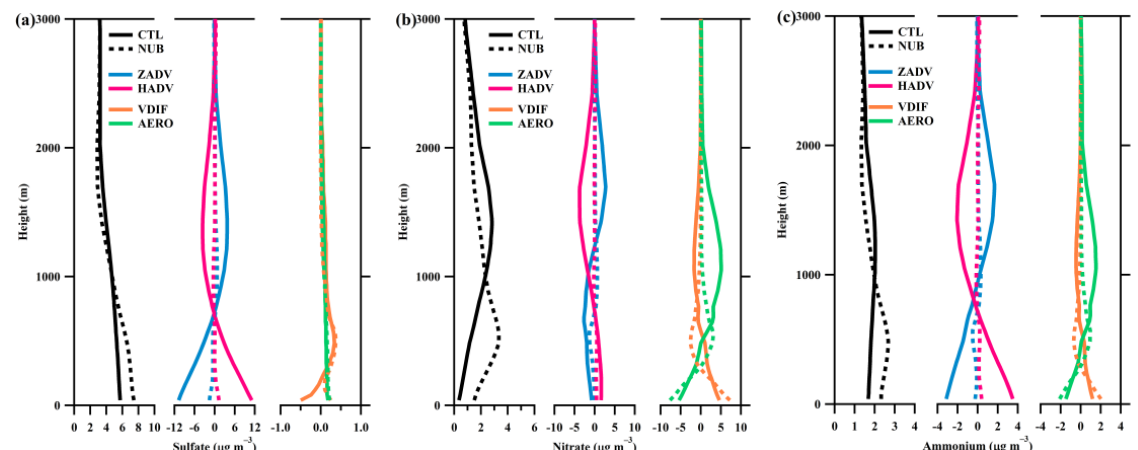

Figure 7. Averaged (12:00-17:00 LT September 18, 2017) vertical profiles of sulfate (a) nitrate (b) and ammonium (c) aerosol concentrations and contributions of vertical advection (ZADV), horizontal advection (HADV), vertical diffusion (VDIF), and aerosol (AERO) processes to their mass concentration in CTL (solid line) and NUB (dashed line) experiments.
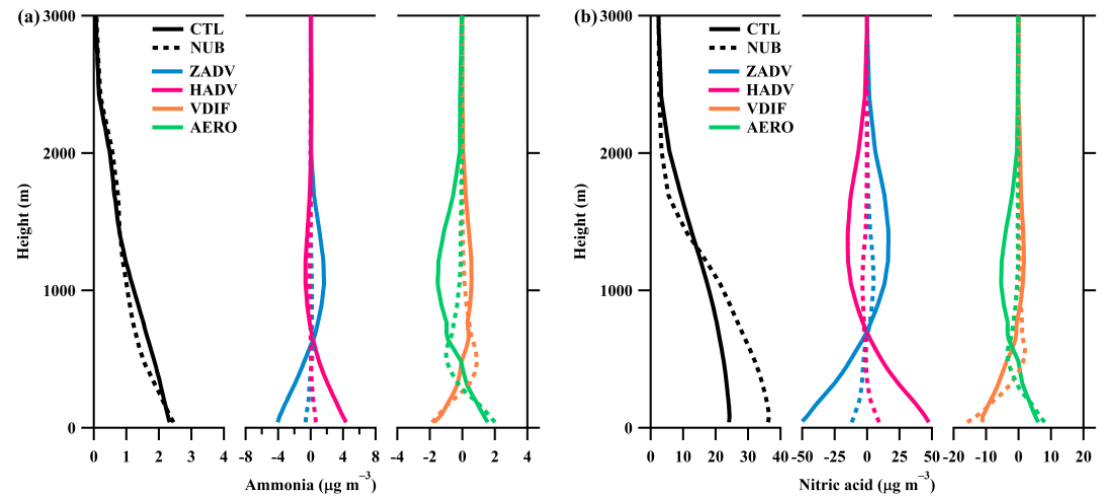

Figure 8. Averaged (12:00-17:00 LT September 18, 2017) vertical profiles of ammonia (a) and gasphase nitric acid (b) concentrations and contributions of vertical advection (ZADV), horizontal advection (HADV), vertical diffusion (VDIF), and aerosol (AERO) processes to their mass concentration in CTL (solid line) and NUB (dashed line) experiments.

The dissociation of ammonium nitrate aerosol strongly depends on the air temperature, and the dissociation constant in the model was calculated using equation 7 (Mozurkewich, 1993):

$$
K=\exp \left[118.87-\frac{24084}{T}-6.025 \ln (T)\right],
$$

where $K$ (nanobar: $\mathrm{nb}^{2}$ ) is the dissociation constant, $T(\mathrm{~K})$ is atmospheric temperature. Air 
temperature over Hangzhou decreased from $30^{\circ} \mathrm{C}$ at ground level to $20^{\circ} \mathrm{C}$ at $1 \mathrm{~km}$ altitude, resulting in the decrease of the dissociation constant from $160 \mathrm{nb}^{2}$ near the surface to $10 \mathrm{nb}^{2}$ at $1 \mathrm{~km}$. Therefore, in the warm lower urban BL, the ammonium nitrate equilibrium (eq. 6) shifts to dissociate into ammonia and nitric acid and at high elevation where the air is colder, the balance is on the side of ammonium nitrate aerosol. Consequently, the peak concentrations of the ammonium and nitrate aerosol profiles appear in the upper atmosphere rather than near ground level (Fig. 7b, 7c), which is consistent with flight observations in California (Neuman, 2003), Cabauw (Aan De Brugh et al., 2012), and model simulations in Milan (Curci et al., 2015). Through vertical diffusion, ammonium nitrate aerosol is transported from the upper air to the lower BL (Fig. 7b, 7c) where it dissociates into ammonia and nitric acid (Fig. 8). Meanwhile, ammonia and nitric acid were transported from ground level to the upper atmosphere by vertical advection and diffusion processes (Fig. 8) and then form ammonium nitrate aerosol.

To compare with $\mathrm{NH}_{4} \mathrm{NO}_{3}$, the dissociation constant for the equilibrium relationship between particle-phase $\left(\mathrm{NH}_{4}\right)_{2} \mathrm{SO}_{4}$, and aqueous-phase $\mathrm{NH}_{4}^{+}$and $\mathrm{SO}_{4}^{2-}$ :

$\left(\mathrm{NH}_{4}\right)_{2} \mathrm{SO}_{4}(\mathrm{~s}) \rightleftharpoons 2 \mathrm{NH}_{4}^{+}(\mathrm{aq})+\mathrm{SO}_{4}^{2-}(\mathrm{aq}),(8)$

was calculated using equation 9 (Kim et al., 1993):

$K=K\left(T_{0}\right)\left[a\left(\frac{T_{0}}{T}-1\right)+b\left(1+\ln \left(\frac{T_{0}}{T}\right)-\frac{T_{0}}{T}\right)\right], \quad(9)$

320 where $T_{0}=298 \mathrm{~K}, K\left(T_{0}\right)=1.817 \mathrm{~mol}^{3} \mathrm{~kg}^{-3}, \mathrm{a}=-2.65$ and $\mathrm{b}=38.57$. The dissociation constant of ammonium sulfate aerosol slowly decreased from $1.892 \mathrm{~mol}^{3} \mathrm{~kg}^{-3}$ near the surface to $1.736 \mathrm{~mol}^{3}$ $\mathrm{kg}^{-3}$ at $1 \mathrm{~km}$. This is why there is less secondary formed sulfate in the LFT (Fig. 7a).

Comparison of the CTL and NUB experiments shows that the CTL experiment produces much more ammonium nitrate aerosol in the upper BL and LFT (Fig. 7b, 7c). This is due to the UHI effect, more ammonia and nitric acid gases and aerosol particles (provide reaction interface for ammonium nitrate) are transported from the surface to higher elevation (Fig. 8), and hence promote the secondary formation of ammonium nitrate aerosols in the cold upper atmosphere. The nitrate and ammonium aerosols formed in the LFT account for approximately $91 \%$ of the total secondary formed aerosol and $20 \%$ of the $\mathrm{PM}_{2.5}$ at that altitude.

In general, the CTL experiment shows that $\mathrm{PM}_{2.5}$ concentration in the lower $\mathrm{BL}$ is reduced by the UHI effect, which can be attributed to the intensified upward transport of aerosol by strong vertical advection and turbulent mixing processes in the urban atmosphere. The larger $\mathrm{PM}_{2.5}$ concentration in the LFT in the CTL simulation is ascribed to the inflow of aerosol by strengthened vertical advection and the secondary formation of inorganic aerosols. However, the impact of enhanced vertical advection and formation of SIA in the urban atmosphere are generally ignored in previous studies.

In the 10-day simulation period, 7 UHI cases occurred in Hangzhou. The average (12:00-17:00 LT each day) UHI intensity of these cases varied from $1.4{ }^{\circ} \mathrm{C}$ to $1.9{ }^{\circ} \mathrm{C}$. Meanwhile, the UHI circulation, which is characterized by vertical wind speed, is strengthened by $0 \mathrm{~cm} \mathrm{~s}^{-1}$ to $10 \mathrm{~cm} \mathrm{~s}^{-1}$ in the BL and $0 \mathrm{~cm} \mathrm{~s}^{-1}$ to $5 \mathrm{~cm} \mathrm{~s}^{-1}$ in the LFT. These UHI effects decreased the $\mathrm{PM}_{2.5}$ concentrations in the $\mathrm{BL}$ by $1 \%$ to $26 \%$, and increased the $\mathrm{PM}_{2.5}$ concentrations in the LFT by $5 \%$ to $21 \%$. The result of the simulations show that the impact of the UHI on aerosol is highly dependent on the intensity of the UHI effect.

\section{Conclusion}

In this study, the impacts of the UHI on the transport, diffusion, formation, and distribution of 
$\mathrm{PM}_{2.5}$, especially SIA, over Hangzhou city were investigated using different simulation experiments with the WRF-BEP-CMAQ model. By comparison of the results from the CTL and NUB experiments, the UHI effects were separated out. The result shows that in the afternoon, due to the UHI effect, the BLH increased by about $0.3 \mathrm{~km}$, and the UHI circulations can penetrate the top of the BL to reach the LFT.

The UHI effect exerted profound impacts on the $\mathrm{PM}_{2.5}$ concentrations over the urban area. When in the model the urban land surface of Hangzhou is replaced with cropland, the ground level $\mathrm{PM}_{2.5}$ would be larger by about $60 \%$. In the afternoon, the $\mathrm{PM}_{2.5}$ concentration in the urban $\mathrm{BL}$ over Hangzhou decreased by $26 \%$ due to the UHI effect, but in the LFT the $\mathrm{PM}_{2.5}$ concentration increased by $21 \%$. This variation is mostly attributed to the effect of UHI circulation (accounting for $\sim 90 \%$ ) rather than the UHI temperature and humidity effects. Process analysis show that UHI circulation strengthens vertical advection, resulting in the transport of a large amount of $\mathrm{PM}_{2.5}$ and its precursors from ground level to the free troposphere. Elevated BL and strengthened turbulence caused by the UHI promoted vertical diffusion of $\mathrm{PM}_{2.5}$, resulting in the decrease of $\mathrm{PM}_{2.5}$ in the lower BL.

Moreover, the UHI effect promoted the secondary formation of inorganic aerosols, especially nitrate and ammonium aerosols, in the upper BL and the LFT by transporting more precursors, e.g., ammonia and nitric acid, from ground level to the upper atmosphere. At higher altitudes, where the air temperature is substantially lower than at the surface, the dissociation constant for ammonium nitrate was reduced, nitrate was driven into the particle phase. The nitrate and ammonium aerosols formed in the upper BL and the LFT accounted for approximately $90 \%$ of the total secondary formed aerosol and $20 \%$ of $\mathrm{PM}_{2.5}$ at that altitude. The UHI-induced SIA increase in the LFT may have implications for the transmission of solar radiation, for cloud formation, and for precipitation in the urban and surrounding areas.

Data availability. The $\mathrm{PM}_{2.5}$ observation data were obtained from a mirror of data from the CNEMC real-time publishing platform (https:/quotsoft.net/air/). The MEIC anthropogenic emission data were acquired from http://meicmodel.org/. Model outputs and $1 \mathrm{~km} \times 1 \mathrm{~km}$ anthropogenic emission data in Hangzhou can be obtained from the authors upon request.

Author contributions. HK was responsible for paper writing, model simulation, and data analysis. BZ proposed the idea and designed the research. GL and RJA contributed to the paper revision and

375 language editing. BY designed the research and provided high resolution anthropogenic emission data. WL performed observation data collection.

Competing interests. The authors declare that they have no conflict of interest.

Acknowledgements. This work was supported by the National Natural Science Foundation of China (Grant No. 92044302 and No. 41605091). The study contributes to the ESA / MOST cooperation project DRAGON5, Topic 3 Atmosphere, sub-topic 3.2 Air-Quality.

\section{References}

Aan de Brugh, J. M. J., Henzing, J. S., Schaap, M., Morgan, W. T., van Heerwaarden, C. C., Weijers, E. P., Coe, H., and Krol, M. C.: Modelling the partitioning of ammonium nitrate in the convective boundary layer, Atmospheric Chemistry and Physics, 12, 3005-3023, 10.5194/acp-12-3005-2012, 2012.

385 Baik, J. J., Kim, Y. H., Kim, J. J., and Han, J. Y.: Effects of boundary-layer stability on urban heat islandinduced circulation, Theoretical and Applied Climatology, 89, 73-81, 10.1007/s00704-006-0254-4, 2006. 
Changnon, S. A.: Rainfall Changes in Summer Caused by St. Louis, Science, 205, 402-404, doi:10.1126/science.205.4404.402, 1979.

Crutzen, P.: New Directions: The growing urban heat and pollution "island" effect—impact on chemistry and climate, Atmospheric Environment, 38, 3539-3540, 10.1016/s1352-2310(04)00297-3, 2004.

Curci, G., Ferrero, L., Tuccella, P., Barnaba, F., Angelini, F., Bolzacchini, E., Carbone, C., Denier van der Gon, H. A. C., Facchini, M. C., Gobbi, G. P., Kuenen, J. P. P., Landi, T. C., Perrino, C., Perrone, M. G., Sangiorgi, G., and Stocchi, P.: How much is particulate matter near the ground influenced by upperlevel processes within and above the PBL? A summertime case study in Milan (Italy) evidences the distinctive role of nitrate, Atmospheric Chemistry and Physics, 15, 2629-2649, 10.5194/acp-15-26292015, 2015.

Emmons, L. K., Walters, S., Hess, P. G., Lamarque, J. F., Pfister, G. G., Fillmore, D., Granier, C., Guenther, A., Kinnison, D., Laepple, T., Orlando, J., Tie, X., Tyndall, G., Wiedinmyer, C., Baughcum, S. L., and Kloster, S.: Description and evaluation of the Model for Ozone and Related chemical Tracers, version 4 (MOZART-4), Geoscientific Model Development, 3, 43-67, 10.5194/gmd-3-43-2010, 2010.

Gao, W., Tie, X., Xu, J., Huang, R., Mao, X., Zhou, G., and Chang, L.: Long-term trend of O3 in a mega City (Shanghai), China: Characteristics, causes, and interactions with precursors, Sci Total Environ, 603604, 425-433, 10.1016/j.scitotenv.2017.06.099, 2017.

Guenther, A. B., Jiang, X., Heald, C. L., Sakulyanontvittaya, T., Duhl, T., Emmons, L. K., and Wang, X.:

405 The Model of Emissions of Gases and Aerosols from Nature version 2.1 (MEGAN2.1): an extended and updated framework for modeling biogenic emissions, Geoscientific Model Development, 5, 1471-1492, 10.5194/gmd-5-1471-2012, 2012.

Kang, H.-Q., Zhu, B., Zhu, T., Sun, J.-L., and Ou, J.-J.: Impact of Megacity Shanghai on the Urban HeatIsland Effects over the Downstream City Kunshan, Boundary-Layer Meteorology, 152, 411-426,

410 10.1007/s10546-014-9927-1, 2014.

Kim, Y. P., Seinfeld, J. H., and Saxena, P.: Atmospheric Gas-Aerosol Equilibrium I. Thermodynamic Model, Aerosol Science and Technology, 19, 157-181, 10.1080/02786829308959628, 1993.

Li, H., Meier, F., Lee, X., Chakraborty, T., Liu, J., Schaap, M., and Sodoudi, S.: Interaction between urban heat island and urban pollution island during summer in Berlin, Sci Total Environ, 636, 818-828, 415 10.1016/j.scitotenv.2018.04.254, 2018.

Li, Y., Zhang, J., Sailor, D. J., and Ban-Weiss, G. A.: Effects of urbanization on regional meteorology and air quality in Southern California, Atmospheric Chemistry and Physics, 19, 4439-4457, 10.5194/acp19-4439-2019, 2019.

Li, Z., Guo, J., Ding, A., Liao, H., Liu, J., Sun, Y., Wang, T., Xue, H., Zhang, H., and Zhu, B.: Aerosol

420 and boundary-layer interactions and impact on air quality, National Science Review, 4, 810-833, 10.1093/nsr/nwx117, 2017.

Liao, J., Wang, T., Jiang, Z., Zhuang, B., Xie, M., Yin, C., Wang, X., Zhu, J., Fu, Y., and Zhang, Y.: WRF/Chem modeling of the impacts of urban expansion on regional climate and air pollutants in Yangtze River Delta, China, Atmospheric Environment, 106, 204-214, 10.1016/j.atmosenv.2015.01.059, 2015.

425 Liu, H., Ma, W., Qian, J., Cai, J., Ye, X., Li, J., and Wang, X.: Effect of urbanization on the urban meteorology and air pollution in Hangzhou, Journal of Meteorological Research, 29, 950-965, 10.1007/s13351-015-5013-y, 2016.

Ma, Y., Ye, J., Xin, J., Zhang, W., Vilà-Guerau de Arellano, J., Wang, S., Zhao, D., Dai, L., Ma, Y., Wu, X., Xia, X., Tang, G., Wang, Y., Shen, P., Lei, Y., and Martin, S. T.: The Stove, Dome, and Umbrella Effects of Atmospheric Aerosol on the Development of the Planetary Boundary Layer in Hazy Regions, 
Geophysical Research Letters, 47, 10.1029/2020g1087373, 2020.

Mozurkewich, M.: The dissociation constant of ammonium nitrate and its dependence on temperature, relative humidity and particle size, Atmospheric Environment. Part A. General Topics, 27, 261-270, 10.1016/0960-1686(93)90356-4, 1993.

435 Narumi, D., Kondo, A., and Shimoda, Y.: The effect of the increase in urban temperature on the concentration of photochemical oxidants, Atmospheric Environment, 43, 2348-2359, 10.1016/j.atmosenv.2009.01.028, 2009.

Neuman, J. A.: Variability in ammonium nitrate formation and nitric acid depletion with altitude and location over California, Journal of Geophysical Research, 108, 10.1029/2003jd003616, 2003.

440 Oke, T. R., Mills, G., Christen, A., and Voogt, J. A.: Urban climates, Cambridge University Press, University Printing House, Cambridge CB2 8BS, United Kingdom, 10.1017/9781139016476, 2017.

Rotach, M. W., Vogt, R., Bernhofer, C., Batchvarova, E., Christen, A., Clappier, A., Feddersen, B., Gryning, S. E., Martucci, G., Mayer, H., Mitev, V., Oke, T. R., Parlow, E., Richner, H., Roth, M., Roulet, Y. A., Ruffieux, D., Salmond, J. A., Schatzmann, M., and Voogt, J. A.: BUBBLE - an Urban Boundary

445 Layer Meteorology Project, Theoretical and Applied Climatology, 81, 231-261, 10.1007/s00704-0040117-9, 2005.

Tao, W.-K., Chen, J.-P., Li, Z., Wang, C., and Zhang, C.: Impact of aerosols on convective clouds and precipitation, Reviews of Geophysics, 50, 10.1029/2011rg000369, 2012.

Wan, H., Zhong, Z., Yang, X., and Li, X.: Impact of city belt in Yangtze River Delta in China on a

450 precipitation process in summer: A case study, Atmospheric Research, 125-126, 63-75, 10.1016/j.atmosres.2013.02.004, 2013.

Wang, Q., Kwan, M. P., Zhou, K., Fan, J., Wang, Y., and Zhan, D.: The impacts of urbanization on fine particulate matter (PM2.5) concentrations: Empirical evidence from 135 countries worldwide, Environ Pollut, 247, 989-998, 10.1016/j.envpol.2019.01.086, 2019.

455 Zhao, B., Jiang, J. H., Gu, Y., Diner, D., Worden, J., Liou, K.-N., Su, H., Xing, J., Garay, M., and Huang, L.: Decadal-scale trends in regional aerosol particle properties and their linkage to emission changes, Environmental Research Letters, 12, 054021, 10.1088/1748-9326/aa6cb2, 2017.

Zhong, S., Qian, Y., Zhao, C., Leung, R., and Yang, X.-Q.: A case study of urbanization impact on summer precipitation in the Greater Beijing Metropolitan Area: Urban heat island versus aerosol effects, 460 Journal of Geophysical Research: Atmospheres, 120, 10,903-910,914, 10.1002/2015jd023753, 2015.

Zhu, B., Kang, H., Zhu, T., Su, J., Hou, X., and Gao, J.: Impact of Shanghai urban land surface forcing on downstream city ozone chemistry, Journal of Geophysical Research: Atmospheres, 120, 4340-4351, 10.1002/2014jd022859, 2015.

Zhu, K., Xie, M., Wang, T., Cai, J., Li, S., and Feng, W.: A modeling study on the effect of urban land

465 surface forcing to regional meteorology and air quality over South China, Atmospheric Environment, 152, 389-404, 10.1016/j.atmosenv.2016.12.053, 2017. 